\title{
Functional and clinical significance of ROR1 in lung adenocarcinoma
}

\author{
Giovanna Schiavone ${ }^{1 * \dagger}$, Samantha Epistolio ${ }^{2 \dagger}$, Vittoria Martin ${ }^{2}$, Francesca Molinari ${ }^{2}$, Jessica Barizzi ${ }^{2}$, \\ Luca Mazzucchelli ${ }^{2}$, Milo Frattini ${ }^{2+}$ and Luciano Wannesson ${ }^{1+}$
}

\begin{abstract}
Background: Receptor tyrosine kinase-like orphan receptor 1 (ROR1) is normally detectable in embryonic tissues and absent in adult tissues. ROR1 was shown to inhibit apoptosis, potentiate EGFR signaling and reported to be overexpressed and associated with poor prognosis in several tumor models. This study aimed to assess the expression of ROR1 in lung adenocarcinoma (AC) patients.
\end{abstract}

Methods: We analyzed ROR1 expression by quantitative real-time PCR (qRT-PCR) in 56 histologically confirmed lung AC, stage I to IV, in addition we evaluated its association with TTF-1 (thyroid transcription factor-1) expression and the main molecular alterations involved in lung cancerogenesis.

Results: ROR1 overexpression was observed in $28.6 \%$ of the entire cohort, using a cut-off of 1 , or in $51.8 \%$ of the cases using the median value as threshold. Among patients without any genetic alteration, ROR1 overexpression was observed in 34.8\% considering a cut-off of 1 and 52.2\% considering the median value. The distribution of ROR1 was homogeneous among the different molecular categories: we found no association of ROR1 expression and the presence of gene mutations/rearrangements or the expression of TTF-1.

Conclusions: ROR1 overexpression could constitute a potential therapeutic target because altered in a consistent number of lung AC, especially in cases without druggable genetic alterations. ROR1 expression is independent of classical lung cancer molecular alterations and not correlated, in a Caucasian cohort, to TTF-1 expression.

Keywords: Non-small cell lung cancer, ROR1, Targeted therapies, Overall survival, EGFR

\section{Background}

Despite several major achievements in the field of targeted and immune treatments for advanced non-small cell lung cancer (NSCLC), especially for the adenocarcinoma (AC) subgroup, this disease still represents a leading cause of death in Europe and worldwide [1]. At a molecular level, lung AC has been extensively characterized, but the enormous body of studies has led to the identification of only a subgroup of patients (cumulatively encompassing no more

\footnotetext{
* Correspondence: giovanna.schiavone@eoc.ch

${ }^{\dagger}$ Giovanna Schiavone and Samantha Epistolio are co-first authors

${ }^{\dagger}$ Milo Frattini and are Luciano Wannesson are co-senior authors

'Istituto Oncologico della Svizzera Italiana, Via Ospedale, 6500 Bellinzona, Switzerland

Full list of author information is available at the end of the article
}

than $25 \%$ of cases) who have a molecular profile favorable to the efficacy of targeted therapies (i.e.: those carrying either EGFR mutations, or ALK, ROS1 or RET gene rearrangements) [2, 3]. Therefore, the identification of new molecular alterations and the development and application of related targeted strategies is essential to improve the prognosis of this disease.

The receptor tyrosine kinase-like orphan receptor 1 (ROR1) is an oncofoetal glycoprotein involved in differentiation, proliferation, migration and survival during the intrauterine development. ROR1 belongs to the ROR receptor tyrosine kinase family, the only other known member of which is ROR2, with a $58 \%$ amino acid sequence coincidence. The structure of human ROR1 comprises

(c) The Author(s). 2020, corrected publication 2020. Open Access This article is licensed under a Creative Commons Attribution 4.0 International License, which permits use, sharing, adaptation, distribution and reproduction in any medium or format, as long as you give appropriate credit to the original author(s) and the source, provide a link to the Creative Commons licence, and indicate if changes were made. The images or other third party material in this article are included in the article's Creative Commons licence, unless indicated otherwise in a credit line to the material. If material is not included in the article's Creative Commons licence and your intended use is not permitted by statutory regulation or exceeds the permitted use, you will need to obtain permission directly from the copyright holder. To view a copy of this licence, visit http://creativecommons.org/ licenses/by/4.0/. The Creative Commons Public Domain Dedication waiver (http://creativecommons.org/publicdomain/zero/1. 0/) applies to the data made available in this article, unless otherwise stated in a credit line to the data. 
one FZ (frizzled) domain, one Ig-like (immunoglobulinlike) C2-type domain, one kringle domain and one protein kinase domain $[4,5]$. ROR1 is normally expressed at high levels during development, becoming repressed in adult tissues. However, a low level of ROR1 expression is seen in adipose tissue and, to a lesser degree, in pancreas, lung and a subset of B cell leukemia [6, 7].

Interestingly, ROR1 may be re-induced during adult carcinogenesis. The expression of ROR1 was reported in numerous blood and solid malignancies, and appears to be involved in the inhibition of apoptosis [8]. In particular, silencing of ROR1 in NSCLC cells disrupts their ability to escape anoikis and anchorage-dependent programmed cell death, and shows decreased primary tumor growth when the cells are transplanted into nude mice. ROR1 seems to induce cell survival through at least two different mechanisms, one is mediated by the interaction with EGFR-Erb$\mathrm{B} 3$ via the PI3K pathway, and the other one is dependent on its kinase activity via the c-SRC pathway [9]. Moreover, a recent study reports that ROR1 enhances lung adenocarcinoma growth by activating the Akt/GSK-3 $\alpha / \beta / \mathrm{mTOR}$ signaling cascade [10].

The observations of low or null ROR1 expression levels in normal adult tissues and its high expression levels in several cancer types led investigators to examine a potential functional advantage to cancer development and growth conferred by ROR1 and to explore the use of therapies against ROR1, that should be specific in cancer cells [11-15]. Yamaguchi and colleagues suggested that TTF-1 (thyroid transcription factor-1), a lineage-survival oncogene often expressed in lung $\mathrm{AC}$, induces ROR1 expression, favoring by this mean a pro-survival PI3K-AKT activity, and opposing to the pro-apoptotic p38 signaling. They demonstrated that ROR1 knockdown inhibited lung AC cell lines, proposing that this receptor could represent a valuable therapeutic target in lung cancer patients [16]. Various putative approaches targeting ROR1 have been developed, such as blockage of its tyrosine kinase activity, the use of ROR1 as a surface target of monoclonal antibodies (MoAbs), [17] the use of MoAb-toxin conjugates (immunotoxins) or via chimeric antigen-receptor T-cells (CAR T-cell) [18].

Based on the observations described above, we hypothesized that ROR1 could be overexpressed in a significant proportion of lung ACs and potentially defines a subgroup of patients eligible for ROR1-targeted therapies. In addition, we aimed to assess the role of TTF-1 in the induction of ROR1 expression in human tissue samples. Finally, we looked for correlations of ROR1 and the main clinical and molecular features. .

\section{Methods}

We investigated 56 lung adenocarcinoma specimens from the database of the Oncology Institute of Southern
Switzerland (Bellinzona, Switzerland) which had enough tissue to perform RNA extraction for the evaluation of ROR1 expression by real-time PCR and to investigate TTF-1 expression, and EGFR, KRAS, BRAF, PIK3CA, HER2, ALK, ROS1 genetic aberrations. We subsequently investigated the association of ROR1 expression and molecular alterations in the whole, in the advanced and in the localized-disease populations. Finally, we analyzed the OS of patients according to ROR 1 and TTF- 1 expression, and to EGFR and KRAS mutations, since the number of patients with ALK, BRAF, PIK3CA, HER2, and ROS1 alterations was too small to allow a survival analysis.

Patients were $\geq 18$ years old and had a histologically confirmed diagnosis of lung AC, stage I to IV as classified according to the seventh edition of the Cancer Staging Manual of the American Joint Committee on Cancer [19]. In our cohort, $7.1 \%$ of the patients had an advanced or metastatic disease and were treated with a palliative intention, while the vast majority (92.9\%) presented localized disease and was treated with a curative intent.

\section{Determination of mutational status of EGFR, KRAS, BRAF, HER2 and PIK3CA by direct sequencing}

Six $7-\mu \mathrm{m}$ thick sections of formalin-fixed paraffinembedded (FFPE) tissue containing at least $70 \%$ tumor cells (after manual microdissection) were cut for direct sequencing (DS) analyses. Genomic DNA was extracted using the QIAamp Mini kit (QIAGEN, Chatsworth, CA, USA) according to the manufacturer's instructions. We searched for point mutations, deletions or insertions in EGFR exons 18-21, in KRAS exon 2, in BRAF exons 11 and 15, in PIK3CA exons 9 and 20, and in HER2 exon 20. The DS approach was based on the Sanger method, performed using a 3130 Genetic Analyzer (Applied Biosystems, Foster City, CA, USA), and the results were analyzed with the corresponding software (Sequencing Navigator, Applied Biosystems). Each sequencing reaction was performed at least twice starting from independent PCR reactions in order to confirm the mutation [20].

\section{ALK and ROS1 FISH analyses}

FISH was performed using LSI ALK Dual Color Break Apart Probe (Abbott Molecular AG, Baar, Switzerland) and SPEC ROS1 Dual Color Break Apart Probe (Zytovision, Bremerhaven, Germany) on 4- $\mu$ m thick FFPE sections, treated by VP2000 Instrument (Abbott Molecular AG, Baar, Switzerland). ALK and ROS1 evaluations were performed following international recommendations and as previously published [21].

\section{TTF-1 immunohistochemistry}

For the evaluation of TTF-1 expression by immunohistochemistry (IHC), a mouse MoAb against TTF-1 


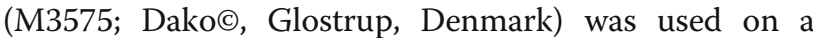
Benchmark XT platform (Ventana-Roche, Tucson, AZ, USA). When tumor cells presented nuclear staining, the case was considered TTF-1-positive. Data indicating the intensity, distribution and percentage of positive cells were also collected.

\section{Determination of ROR1 expression by real-time PCR}

RNA was extracted from two $10-\mu \mathrm{m}$ thick FFPE tissue sections. For each patient, tumor (containing at least $70 \%$ of tumor cells) and paired adjacent normal specimens were analyzed. RNA extraction was performed using the RNeasy FFPE kit (QIAGEN) according to the manufacturer's instructions. For each specimen, $500 \mathrm{ng}$ of RNA was retro transcribed into complementary DNA (cDNA) using the Superscript Vilo Mastermix III (Invitrogen, Carlsbad, CA, USA). ROR1 expression was evaluated by assays using a TaqMan fluorescent probe (Applied Biosystems) that recognizes the target gene (i.e., ROR1) and a TaqMan probe marked with a different fluorochrome that recognizes a reference gene (i.e., the RN18S1 housekeeping gene which encodes the $18 \mathrm{~S}$ rRNA). For analysis of each specimen, $100 \mathrm{ng}$ of retro transcribed RNA were used, and the amplification was performed in triplicate. The relative expression level was calculated with the Livak method, which standardizes the target gene to the reference gene in both tumor and normal tissues through the $2^{[-\Delta \Delta C(T)]}$ formula. Gene expression levels were expressed as the fold change \pm standard deviation. The specificity was determined by the analysis of the melting curves [22]. The real-time data were analyzed considering the threshold cycle in both cancer and normal tissues for each sample. $\Delta \Delta \mathrm{Ct}$ is the difference between the sample $\Delta \mathrm{Ct}$ and the control $\Delta \mathrm{Ct}$. Sample $\Delta \mathrm{Ct}$ is the difference between the $\mathrm{Ct}$ of the target gene (ROR1) and the Ct of the reference gene in tumor tissue. Control $\Delta \mathrm{Ct}$ is the difference between the $\mathrm{Ct}$ of the target gene (ROR1) and the $\mathrm{Ct}$ of the reference gene in normal tissue. The cut-off value (r) for ROR1 overexpression was set-up at 1 : cases showing $r>1$ values were considered as ROR1 overexpressed, cases showing $r \leq 1$ values were considered as having a normal expression of ROR1. We fixed 1 as cut-off because in literature a standard value to follow for the evaluation of ROR1 expression is not reported. We decided the threshold of $r=1$ because the calculations of the Livak value generally are equal to 1 when the expression of a gene is comparable between normal and tumor tissues of the same patient. Furthermore, in agreement with another work of our group, we decided to subdivide the cohort on the basis of the median value [23].

\section{Statistical considerations}

Demographic data and baseline characteristics of patients and disease were analyzed with standard summary statistics (mean SD and range for continuous data, relative and absolute frequencies for categorical data). Relationship of selected biomarkers with baseline factors and other biomarkers were analyzed by mean of a $x^{2}$ test. Time to event analysis was described by Kaplan Meier approach and the association with baseline characteristic was analyzed by proportional hazard model. For biomarker based on continuous scales, median and selected cut-off values were used.

\section{Results}

Among the 56 lung adenocarcinoma samples, qRT-PCR showed ROR1 overexpression in 16 cases (28.6\%) considering a cut-off value $r=1$, while accounting for the median, patients with ROR1 overexpression were 29 (51.8\%). The level of ROR1 overexpression, assessed both by the cut-off value ( $r>1$ vs $r \leq 1$ ) (Fig. 1a, b and c) and the median one (over and below the median value) (Fig. 2a, b and c) was not associated with overall survival (OS) and this observation was independent of the tumor stage.

Concerning the main alterations clinically relevant in lung cancers, about $9 \%$ of patients had an $\mathrm{AC}$ harboring
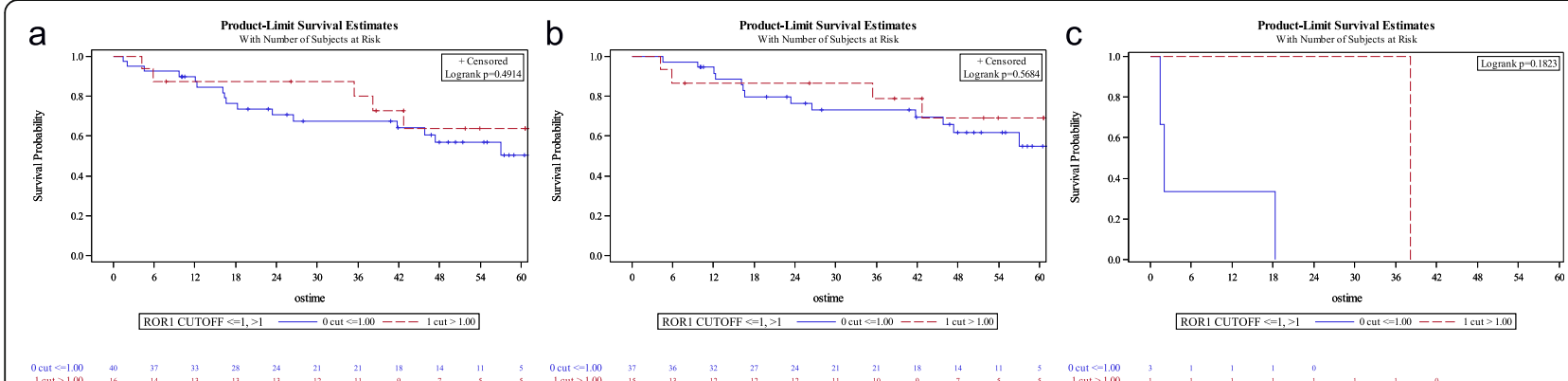

Fig. 1 a Overall survival (OS): ROR1 by cut-off in the general population; b OS by ROR1 in localized disease population (cut-off); c OS by ROR1 in advanced disease population (cut-off) 


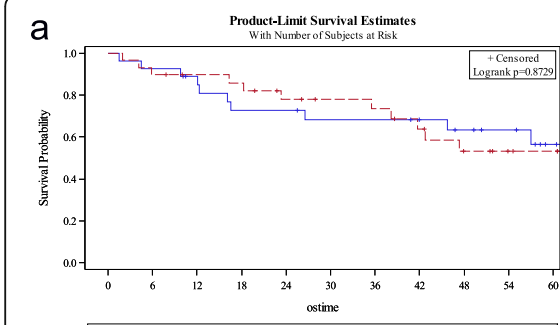

RORI CUTOFF $<=$ median, $>$ median $-1: 0$ cut $<-$ nedian $---2: 1$ cut $>$ medial

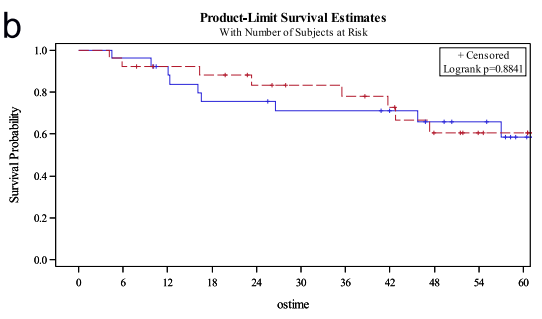

RORI CUTOFF $\leqslant=$ median, $>$ median $-1: 0$ cut $<-$ median $---2:$ cut $>$ median

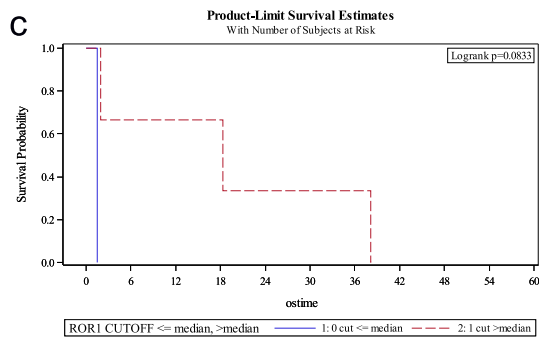

RORI CUTOFF $<=$ median, $>$ median $-1: 0$ cut $<=$ median $---2: 1$ cut $>$ median

Fig. 2 a Overall survival (OS) by median ROR1 expression; b OS by median ROR1 in localized disease population; c OS by median ROR1 in advanced disease population

a classical EGFR mutation (exon 19 deletions or the exon 21 point mutation L858R). One patient presented EGFR mutation and ALK rearrangement simultaneously, while no patients showed an ALK rearrangement alone. A KRAS mutation was found in $46.4 \%$ of the patient population, constituting the most frequent genetic aberration. BRAF and HER2 mutations were found in one patient each, while no cases with ROS1 gene rearrangements were observed. As most of the tumor samples were initially evaluated in a pre-immunotherapy period, information on PD-L1 expression was not available and could not be evaluated prospectively due to insufficient tissue availability. The baseline patients' and disease characteristics are summarized in Table 1.

Among our patients without a genetic alteration, we found ROR1 overexpression in 34.8 and $52.2 \%$, defined by $r=1$ and a value over the median level of expression, respectively.

We also analyzed potential correlations between OS and ROR1 stratifying by the mutational status of the main markers involved in lung carcinogenesis and disease stage. In particular, we focused the attention on EGFR and KRAS mutations, because the alterations in the other genes were too rare. The distribution of ROR1 was homogeneous among the different mutational categories; in particular, we found no association of ROR1 expression and the presence of EGFR or KRAS mutations. Moreover, we did not find any correlation between ROR1 and TTF- 1 expressions, unlike suggested by other authors in an Asian population [24] (Table 2).

Parallel statistical evaluations demonstrated that, in our patient cohort, there were no differences in OS of patients with EGFR mutated lung adenocarcinoma versus those with EGFR wild-type tumors, irrespective of the stage $(p=0.9875)$. Among patients with advanced stage, the presence of EGFR-mutation had a nonsignificant trend to a better OS comparing to patients with localized disease $(p=0.0703)$. For patients with localized disease, the OS curves of the EGFR wild-type and mutated populations were superimposable $(p=$ 0.8529).

Similarly, the presence or absence of a KRAS mutation did not have a correlation with OS $(p=0.8160)$. Patients with KRAS wild-type and localized disease were found to have a non-significant trend to a better OS ( $p=$ 0.0767); however, in those with advanced disease, the OS was similar regardless of the presence or absence of a KRAS mutation $(p=0.8887)$.

TTF-1 was found to be consistently expressed in 80 , $3 \%$ of our cohort but was not associated with OS neither in general $(p=0.1619)$ nor in the localized $(p=0.3601)$

Table 1 Patient's characteristics

\begin{tabular}{ll}
\hline Patient's Characteristics & no. (\%) \\
\hline Sex & \\
Male & $26 / 56(46.4 \%)$ \\
Female & $30 / 56(53.6 \%)$ \\
Race & \\
$\quad$ Caucasian & $56 / 56(100 \%)$ \\
Stage of disease at diagnosis & \\
I/IIIIIA & $52 / 56(92.9 \%)$ \\
IIIB/IV & $4 / 56(7.1 \%)$ \\
Histologic Type & \\
Adenocarcinoma & $56 / 56(100 \%)$ \\
Mutation present & \\
ROR1 & $16 / 56(28.6 \%)$ \\
EGFR & $5 / 56(8.9 \%)$ \\
KRAS & $26 / 56(46.4 \%)$ \\
ALK & $1 / 9(11.1 \%)$ \\
BRAF & $1 / 54(1.9 \%)$ \\
HER2 & $1 / 55(1.8 \%)$ \\
TTF-1 & $45 / 56(80.3 \%)$ \\
ROS1 & $0 / 45(0 \%)$ \\
\hline Descipton & \\
\hline
\end{tabular}

Description of the clinicopathological features and of the mutational characterization of the cohort included in this study. Patient's characteristics subgroups are reported in bold. Abbreviations: no number. 
Table 2 Association of ROR1 with: TTF-1 expression; EGFR, KRAS mutations by median and cut-off

\begin{tabular}{|c|c|c|c|c|c|c|c|}
\hline \multicolumn{2}{|c|}{ Overall population } & \multicolumn{6}{|c|}{ ROR1 expression } \\
\hline & & \multirow{2}{*}{$\begin{array}{l}\leq \text { median } \\
25\end{array}$} & \multirow{2}{*}{$\begin{array}{l}\text { >median } \\
26\end{array}$} & \multirow{2}{*}{$\begin{array}{l}p \text { value } \\
0.7027\end{array}$} & \multirow{2}{*}{$\begin{array}{l}\text { cut-off } \leq \mathbf{1} \\
37\end{array}$} & \multirow{2}{*}{$\begin{array}{l}\text { cut-off }>\mathbf{1} \\
14\end{array}$} & \multirow{2}{*}{$\frac{p \text { value }}{0.5569}$} \\
\hline EGFR & wt & & & & & & \\
\hline & mut & 2 & 3 & & 3 & 2 & \\
\hline \multirow[t]{2}{*}{ KRAS } & wt & 14 & 16 & 0.8051 & 20 & 10 & 0.4011 \\
\hline & mut & 13 & 13 & & 20 & 6 & \\
\hline \multirow[t]{2}{*}{ TTF-1 } & neg & 6 & 5 & 0.6422 & 8 & 3 & 0.9161 \\
\hline & pos & 21 & 24 & & 32 & 13 & \\
\hline \multirow{2}{*}{\multicolumn{2}{|c|}{ Localized disease }} & \multicolumn{6}{|c|}{ ROR1 expression } \\
\hline & & $\leq$ median & >median & $p$ value & cut-off $\leq 1$ & cut-off $>1$ & $p$ value \\
\hline \multirow[t]{2}{*}{ EGFR } & wt & 24 & 23 & 0.6413 & 34 & 13 & 0.5663 \\
\hline & mut & 2 & 3 & & 3 & 2 & \\
\hline \multirow[t]{2}{*}{ KRAS } & wt & 13 & 14 & 0.7834 & 17 & 10 & 0.1797 \\
\hline & mut & 13 & 12 & & 20 & 5 & \\
\hline \multirow[t]{2}{*}{ TTF-1 } & neg & 6 & 5 & 0.7367 & 8 & 3 & 0.8978 \\
\hline & pos & 20 & 21 & & 29 & 12 & \\
\hline \multirow{2}{*}{\multicolumn{2}{|c|}{ Advanced disease }} & \multicolumn{6}{|c|}{ ROR1 expression } \\
\hline & & $\leq$ median & >median & $p$ value & cut-off $\leq 1$ & cut-off $>1$ & $\mathrm{p}$ value \\
\hline \multirow[t]{2}{*}{ EGFR } & wt & 1 & 3 & 0 & 3 & 1 & 0 \\
\hline & mut & 0 & 0 & & 0 & 0 & \\
\hline \multirow[t]{2}{*}{ KRAS } & wt & 1 & 2 & 0.5637 & 3 & 0 & 0.0833 \\
\hline & mut & 0 & 1 & & 0 & 1 & \\
\hline \multirow[t]{2}{*}{ TTF-1 } & neg & 0 & 0 & 0 & 0 & 0 & 0 \\
\hline & pos & 1 & 3 & & 3 & 1 & \\
\hline
\end{tabular}

Statistical evaluation of ROR1 expression distribution, estimated by the median and the cut-off (equal to 1), among the analyzed molecular markers: EGFR, KRAS mutations; TTF-1 expression. The $p$ values results and the severity of the disease are reported in bold

or advanced disease populations $(p=0.1707)$. TTF- 1 expression was not correlated with ROR1 expression.

\section{Discussion}

In recent years, relevant improvements in the treatment of lung AC were achieved, especially by virtue of the introduction of tailored treatment acting against specific molecular targets and immunotherapy with checkpoint inhibitors [25-28]. Nevertheless, the 5-year OS rates remain unsatisfactory for a significant number of patients without a druggable mutation or low/negative PD-L1 expression. The identification of novel predictive and prognostic biomarkers as well as potential targets for novel treatment strategies is therefore of great importance.

ROR1 is an embryonic protein which plays a fundamental role in cardiorespiratory, neurological and skeleton development, but its expression is very rare in adult tissues [8]. In the other hand, some studies reported that ROR1 could be overexpressed by several hematological and solid malignancies [15, 29-31]. The specific expression of ROR1 by tumor cells and its absence in normal tissues makes of this receptor an ideal theoretical target for cancer treatment. The relevance of ROR1 and its therapeutic role has been recently explored in ovarian cancer. Indeed, it has been demonstrated that ROR1 has an important therapeutic role in such a neoplastic disease because glucocorticoids anti-inflammatory agents (generally administred as adjuvant to chemotherapy) may induce chemoresistance by promoting ROR1mediated stemness [32].

Preliminary studies on ROR1 expression in human lung AC either included a small number of patients or were conducted on cell lines. Zhang and colleagues studied 29 lung AC patients and showed that 59\% presented a strong expression of ROR1 by IHC [14]. Karachaliou and co-workers assessed ROR1 mRNA expression in 27 NSCLC patients with the EGFR-T790M mutation, showing that high ROR1 expression is associated with a significantly shorter progression-free survival in erlotinibtreated patients, but not in chemotherapy-treated patients [33]. The results of a study by Zheng and colleagues revealed that ROR1 protein expression was significantly higher in lung $\mathrm{AC}$ tissue than in the adjacent normal tissue. Furthermore, patients with advanced 
disease showed higher levels of ROR1 expression, and this study revealed an association between high ROR1 expression and worse OS [24].

In the present study, we examined the mRNA expression of ROR1 in 56 lung adenocarcinoma patients by qRT-PCR. We decided to use an objective methodology (i.e.: qRT-PCR) because very often the evaluation of IHC staining is difficult and can vary depending on time and type of fixation. Furthermore, there is no a specific and widely approved antibody for $\mathrm{IHC}$, the procedure for the evaluation of ROR1 protein expression is not standardized and the results obtained using different antibodies can give not reproducible results, as clearly demonstrated by several contributions, including one where three different antibodies, evaluated with three different instruments, were compared for assessing the expression of another receptor tyrosine kinase like EGFR (located in plasma membrane, as ROR1). An open discussion topic is represented by the cut-off value for the definition of expression of genes by qRT-PCR, due to the lack of consensus in the literature. We hence decided to use two different definitions: the median value (that is cohortdependent but represents the wider approach in the literature) and the value of $r=1$, that indicates a clear overexpression (if $>1$ ) with respect to a normal expression $(\leq 1)$. In our cohort, we found relevant rates of ROR1 mRNA overexpression even when the cut-off $r=$ 1 was used (28.6\%). This proportion is increased when we focused on patients without any mutation in the genes traditionally involved in lung carcinogenesis such as EGFR, KRAS, BRAF, HER2, ALK, ROS1 (34.8 and $52.2 \%$ when we applied the cut-off of $r=1$ or of the median value, respectively), supporting the hypothesis that ROR1 could constitute a potential tumor driver in a significant number of lung AC. To our best knowledge, this is the first assessment of ROR1 on a Caucasian cohort of patients. Unlike a previous report conducted on a cohort of Asian patients that suggested that ROR1 overexpression is induced by TTF-1, [16] we did not find any correlation between ROR1 mRNA levels and TTF-1 expression. Furthermore, in contrast to previously reports, [34-36] in our patient cohort TTF-1 expression was not prognostic for survival, although we acknowledge that this result could be biased by the low number of patients that we analyzed.

ROR1 expression was homogeneously distributed among the different tumor types, sorted by mutation status. We found, in fact, no correlation between expression of ROR1 and the presence of EGFR and KRAS mutations. Finally, we did not find any correlation between ROR1 expression (irrespectively of the cut-of value used) and survival.

A corollary of the analysis of ROR1 was the evaluation, in terms of prognostic factor, of EGFR or KRAS mutations. In our cohort, there were no differences in OS of patients with EGFR mutated lung AC versus those with EGFR wild-type tumors, irrespective of the stage of the disease. This result was probably due to a prevalence of resected cases over advanced, non-resected stages. Among our few patients with an advanced stage, EGFRmutated disease had a non-significant trend to a better OS. For patients with localized disease, the OS curves were superimposable. This phenomenon may be explained by the fact that less resected patients with EGFR mutated disease undergo progression and eventually benefit from anti-EGFR TKI therapy.

\section{Conclusions}

In conclusion, our study demonstrates that ROR1 overexpression in lung $\mathrm{AC}$ occurs in a significant number of patients, suggesting a potential role of ROR1 as a therapeutic target, especially for patients who cannot be treated with current targeted therapies due to the lack of molecular alterations in their cancers. Standardization of the assessment of ROR1 protein expression is still pending.

\section{Abbreviations \\ AC: Adenocarcinoma; CAR T-cell: Chimeric antigen-receptor T-cells; CDNA: Complementary DNA; DS: Direct sequencing; FFPE: Formalin-fixed paraffin-embedded; FZ: Frizzled domain; Ig-like: Immunoglobulin-like; IHC: Immunohistochemistry; MoAb: Monoclonal antibody; NSCLC: Non-small cell lung cancer; OS: Overall survival; qRT-PCR: Quantitative real-time PCR; ROR1: Receptor tyrosine kinase-like orphan receptor 1; TTF-1: Thyroid transcription factor-1}

\section{Acknowledgements}

Not applicable.

\section{Authors' contributions}

GS collected all clinical data and wrote the first draft of the manuscript. SE performed all the molecular characterization and wrote the first draft of the manuscript. VM did the evaluation of FISH experiments. FM evaluated DNA sequences. JB selected all the specimens at histologic level. LM evaluated $I \mathrm{HC}$ experiments. MF evaluated gene expression of ROR1, supervised the whole project and prepared the final version of the manuscript. LW supervised the whole project and prepared the final version of the manuscript. All authors have read and approved the manuscript.

\section{Funding}

This work was supported by an Advisory Board of Research of Ente Ospedaliero Cantonale (ABREOC) fund (grant number 22062). ABREOC provided all the funds necessary for the collection of cases, the analyses of results, the statistical interpretation of the data and for the submission of the manuscript.

\section{Availability of data and materials}

The datasets used and analysed during the current study are available from the corresponding author upon request.

\section{Ethics approval and consent to participate}

The work described has been carried out in accordance with The Code of Ethics of the World Medical Association (Declaration of Helsinki) for

experiments involving humans. The project was approved by the ethics local committee (cantonal ethics committee, Sanity Office, Via Orico 5, 6501

Bellinzona). All the partecipants signed an informed consent to partecipate in this study and a consent for the publication of the anonymized data has also been obtained. 


\section{Consent for publication}

Not applicable.

\section{Competing interests}

The authors declare that they have no competing interests.

\section{Author details}

'Istituto Oncologico della Svizzera Italiana, Via Ospedale, 6500 Bellinzona, Switzerland. ${ }^{2}$ Istituto Cantonale di Patologia, Via in Selva 24, 6600 Locarno, Switzerland.

Received: 21 July 2020 Accepted: 29 October 2020

Published online: 10 November 2020

\section{References}

1. Siegel RL, Miller KD, Jemal A. Cancer statistics, 2018. CA Cancer J Clin. 2018; 6(1):7-30.

2. Rebuzzi SE, Alfieri R, La Monica S, et al. Combination of EGFR-TKls and chemotherapy in advanced EGFR mutated NSCLC: review of the literature and future perspectives. Crit Rev Oncol Hematol. 2020;146:102820.

3. Rosas G, Ruiz R, Araujo JM, et al. ALK rearrangements: biology, detection and opportunities of therapy in non-small cell lung cancer. Crit Rev Oncol Hematol. 2019:136:48-55

4. Masiakowski $P$, Carroll RD. A novel family of cell surface receptors with tyrosine kinase-like domain. J Biol Chem. 1992;267(36):26181-90.

5. Nomi M, Oishi I, Kani S, et al. Loss of mRor1 enhances the heart and skeletal abnormalities in mRor2-deficient mice: redundant and pleiotropic functions of mRor 1 and mRor2 receptor tyrosine kinases. Mol Cell Biol. 2001;21(24): 8329-35.

6. Broome HE, Rassenti LZ, Wang HY, et al. ROR1 is expressed on hematogones (nonneoplastic human B-lymphocyte precursors) and a minority of precursor-B acute lymphoblastic leukemia. Leuk Res. 2011;35(10): 1390-4.

7. Minami Y, Oishi I, Endo M, et al. Ror-family receptor tyrosine kinases in noncanonical Wnt signaling: their implications in developmental morphogenesis and human diseases. Dev Dyn. 2010;239(1):1-15.

8. Borcherding N, Kusner D, Liu GH, et al. ROR1, an embryonic protein with an emerging role in cancer biology. Protein Cell. 2014:5(7):496-502.

9. Gentile A, Lazzari L, Benvenuti S, et al. Ror1 is a pseudokinase that is crucial for met-driven tumorigenesis. Cancer Res. 2011;71:3132-41.

10. Zhou Q, Zhou S, Wang H, et al. Stable sequencing of ROR1 regulates cell cycle, apoptosis, and autophagy in a lung adenocarcinoma cell line. Int J Clin Exp Pathol. 2020;13(5):1108-20.

11. Baskar S, Kwong KY, Hofer $T$, et al. Unique cell surface expression of receptor tyrosine kinase ROR1 in human B-cell chronic lymphocytic leukemia. Clin Cancer Res. 2008;14(2):396-404.

12. Barna $G$, Mihalik R, Timár $B$, et al. ROR1expression is not a unique marker of CLL. Hematol Oncol. 2011;29(1):17-21.

13. Zhang S, Chen L, Cui B, et al. ROR1 is expressed in human breast cancer and associated with enhanced tumor-cell growth. PLoS One. 2012;7(3): e31127.

14. Zhang S, Chen L, Wang-Rodriguez J, et al. The onco-embryonic antigen ROR1 is expressed by a variety of human cancers. Am J Pathol. 2012;181(6): 1903-10.

15. Daneshmanesh AH, Porwit A, Hojjat-Farsangi M, et al. Orphan receptor tyrosine kinases ROR1 and ROR2 in hematological malignancies. Leuk Lymphoma. 2013:54(4):843-50.

16. Yamaguchi T, Yanagisawa K, Sugiyama R, et al. NKX2-1/TITF1/TTF-1-induced ROR1 is required to sustain EGFR survival signaling in lung adenocarcinoma. Cancer Cell. 2012;21:348-61.

17. Rebagay G, Yan S, Liu C, et al. ROR1 and ROR2 in human malignancies: potentials for targeted therapy. Front Oncol. 2012;2:34.

18. Huang X, Park H, Greene J, et al. IGF1R- and ROR1-specific CAR T cells as a potential therapy for high risk sarcomas. PLoS One. 2015;10:e133152.

19. Edge SB, Byrd DR, Compton CC, et al. AJCC cancer staging manual. 7th ed. New York: Springer; 2010

20. Sahnane N, Frattini M, Bernasconi B, et al. EGFR and KRAS mutations in ALKpositive lung adenocarcinomas: biological and clinical effect. Clin Lung Cancer. 2016;17:56-61.
21. Martin V, Bernasconi B, Merlo E, et al. ALK testing in lung adenocarcinoma: technical aspects to improve FISH evaluation in daily practice. J Thorac Oncol. 2015;10(4):595-602.

22. Livak KJ, Schmittgen TD. Analysis of relative gene expression data using real-time quantitative PCR and the 2(-Delta Delta C(T)) method. Methods. 2001;25(4):402-8

23. Forcella M, Mozzi A, Stefanini FM, et al. Deregulation of sialidases in human normal and tumor tissues. Cancer Biomark. 2018;21(3):591-601.

24. Zheng YZ, Ma R, Zhou JK, et al. ROR1 is a novel prognostic biomarker in patients with lung adenocarcinoma. Sci Rep. 2016;6:36447.

25. Gandhi L, Rodríguez-Abreu D, Gadgeel S, et al. Pembrolizumab plus chemotherapy in metastatic non-small-cell lung cancer. N Engl J Med. 2018:378:2078-92

26. Reck M, Rodriguez-Abreu D, Robinson AG, et al. Pembrolizumab versus chemotherapy for PD-L1-positive non-small cell lung cancer. N Engl J Med. 2016;375:1823-33.

27. Soria JC, Ohe $Y$, Vansteenkiste J, et al. Osimertinib in untreated EGFRmutated advanced non-small-cell lung cancer. N Engl J Med. 2018;378: $113-25$.

28. Peters S, Camidge R, Alice TS, et al. Alectinib versus Crizotinib in untreated ALK-positive non-small-cell lung cancer. N Engl J Med. 2017;377(9):829-38.

29. Rabbani H, Ostadkarampour M, Danesh Manesh AH, et al. Expression of ROR1 in patients with renal cancer-a potential diagnostic marker. Iran Biomed J. 2010;14:77-82

30. Hojjat-Farsangi M, Ghaemimanesh F, Daneshmanesh AH, et al. Inhibition of the receptor tyrosine kinase ROR1 by anti-ROR1 monoclonal antibodies and siRNA induced apoptosis of melanoma cells. PLoS One. 2013;8:e61167.

31. Zhang H, Qiu J, Ye C, et al. ROR1 expression correlated with poor clinical outcome in human ovarian cancer. Sci Rep. 2014;4:5811.

32. Karvonen $H$, Arjama $M$, Kaleva $L$, et al. Glucocoticoids induce differentiation and chemoresistance in ovarian cancer by promoting ROR1-mediated stemness. Cell Death Dis. 2020;11(9):790.

33. Karachaliou N, Gimenez-Capitan A, Drozdowskyj A, et al. ROR1 as a novel therapeutic target for EGFR-mutant non-small-cell lung cancer patients with the EGFR T790M mutation. Transl Lung Cancer Res. 2014;3:122-30.

34. Grønberg BH, Lund-Iversen M, Strøm EH, et al. Associations between TS, TTF-1, FR-a, FPGS, and overall survival in patients with advanced non-smallcell lung cancer receiving pemetrexed plus carboplatin or gemcitabine plus carboplatin as first-line chemotherapy. J Thorac Oncol. 2013;8(10):1255-64.

35. Schilsky JB, Ni A, Ahn L, et al. Lung Cancer. 2017;108:205-11.

36. Qiann $\mathrm{HH}$, Xu TS, Cai XQ, et al. Prognostic value of TTF-1 expression in patients with non-small cell lung cancer: a meta-analysis. Clin Chim Acta. 2015;451:208-14.

\section{Publisher's Note}

Springer Nature remains neutral with regard to jurisdictional claims in published maps and institutional affiliations.

Ready to submit your research? Choose BMC and benefit from:

- fast, convenient online submission

- thorough peer review by experienced researchers in your field

- rapid publication on acceptance

- support for research data, including large and complex data types

- gold Open Access which fosters wider collaboration and increased citations

- maximum visibility for your research: over $100 \mathrm{M}$ website views per year

At BMC, research is always in progress.

Learn more biomedcentral.com/submissions 